\title{
A multicenter, primary care-based, open-label study to identify behaviors related to prescription opioid misuse, abuse, and diversion in opioid-experienced patients with chronic moderate-to-severe pain
}

\author{
This article was published in the following Dove Press journal: \\ Journal of Pain Research \\ 9 July 2015 \\ Number of times this article has been viewed
}

\author{
Beatrice Setnik' \\ Carl L Roland' \\ Kenneth W Sommerville ${ }^{1,2}$ \\ Glenn C Pixton' \\ Robert Berke 3,4 \\ Anne Calkins ${ }^{5}$ \\ Veeraindar Goli ${ }^{1,2}$ \\ 'Pfizer Inc, ${ }^{2}$ Duke University Medical \\ Center, Durham, NC, ${ }^{3}$ Family Health \\ Medical Services PLLC, Mayville, NY, \\ ${ }^{4}$ Department of Social and Preventive \\ Medicine, State University of New \\ York at Buffalo, Buffalo, NY, ${ }^{5} \mathrm{New}$ York \\ Spine \& Wellness Center, Syracuse, \\ NY, USA
}

\begin{abstract}
Objective: To compare the investigator assessment of patient risk for prescription opioid misuse, abuse, and diversion with patient self-reports of these activities in a population with chronic pain.

Methods: As a secondary objective of an open-label, multicenter, primary care-based clinical study to evaluate the success of converting opioid-experienced patients with chronic pain to morphine sulfate with sequestered naltrexone hydrochloride, risk for misuse, abuse, and diversion was assessed using two nonvalidated questionnaires: one was completed by the investigator and another by the patient (Self-Reported Misuse, Abuse, and Diversion [SR-MAD]). In addition, the validated Current Opioid Misuse Measure (COMM) test and urine drug test were used.

Results: Of the 684 patients assessed by the investigators, 537 returned the self-assessment, SR-MAD. Most patients were assigned by the investigator as low risk for misuse ( $84.2 \%)$, abuse (89.3\%), and diversion (94.3\%). Of the patients who returned SR-MAD, $60 \%$ indicated having taken more opioids than prescribed and $10.9 \%$ reported chewing or crushing their opioids in the past. Of the patients who completed COMM, 40.6\% were deemed as having aberrant behaviors. COMM results correlated with the risk levels from the investigator assessment. One-third of patients (33.8\%) had at least one abnormal urine drug test result.

Conclusion: More research is needed to better understand the gap between the investigator assessment of potential risk for misuse, abuse, and diversion and the actual extent of these behaviors among patients with chronic pain.
\end{abstract}

Keywords: opioid, abuse, misuse, diversion, chronic pain

\section{Introduction}

Prescription opioids can be safe and effective medications for treatment of acute and chronic pain if used as prescribed and appropriately monitored. ${ }^{1}$ The number of prescriptions filled for opioid medications has increased dramatically in the recent years, and at the same time, misuse, abuse, and diversion have been on the rise. ${ }^{2-4}$

The estimated number of emergency department (ED) visits related to nonmedical use of prescription opioids has increased 183\%, from 172,738 in 2004 to 488,004 in 2011..$^{5}$ According to the Centers for Disease Control and Prevention, the death rate related to prescription opioid poisoning increased dramatically from 1999 to 2010 (1.4-5.4 deaths per 100,000 persons, respectively). ${ }^{6}$ Because prescription opioids are widely used for the management of pain, it is important to balance patients' legitimate needs for analgesia with the urgent public need to reduce drug misuse, abuse,
Correspondence: Beatrice Setnik INC Research, Early Phase, 320 I Beechleaf Court, Suite 600, Raleigh, NC 27604, USA

Tel + I 9192275854

Fax + I 9198769360

Email beatrice.setnik@incresearch.com 
and diversion. Providing clinicians with assessment tools to identify characteristics of patients at high risk for drug misuse, abuse, and diversion could mitigate the risk for these aberrant behaviors and enhance the health benefits associated with prescription opioids.

Several risk assessment tools have been developed to evaluate aberrant behavior associated with prescription opioids..$^{7-10}$ Some tools are designed to predict the future aberrant opioid-related behaviors in patients with chronic pain who are considered for chronic opioid therapy; these tools include the Opioid Risk Too ${ }^{11}$ and Screener and Opioid Assessment for Patients with Pain-Revised (SOAPP-R). ${ }^{12}$ Other tools are designed to identify drug-related aberrant behavior in patients currently taking opioids and include the Current Opioid Misuse Measure (COMM), pain medication questionnaire, and prescription drug use questionnaire. ${ }^{10,13,14}$ All these instruments demonstrated some utility by either predicting risk for or evaluating current aberrant behavior associated with prescription opioids, but none of them are able to discriminate between misuse and abuse in the pain patient population and there is underrepresentation of diversion. Additionally, the currently available tools lack information on tampering and routes of administration.

Few studies have estimated misuse, abuse, and diversion in patients with chronic pain, likely due to the lack of available instruments and methodology. In a 1-year prospective cohort study of predictors of opioid misuse in patients with chronic pain, 32\% were found to misuse their opioid medications, and the strongest predictors of misuse were self-reported histories of previous alcohol, cocaine abuse, previous criminal drug-, or alcohol-related convictions. ${ }^{15}$ A study that used SOAPP-R to evaluate the potential for and incidence of aberrant drugrelated behaviors among 1,487 patients with chronic pain in a primary care setting assigned $21 \%$ of the patients as low risk, $54 \%$ as moderate risk, and $25 \%$ as high risk for potential aberrant drug-related behavior. ${ }^{16}$ When SOAPP-R scores were combined with signs of aberrant drug-related behavior and investigator judgment, the investigators assigned a higher number of patients as low risk (47\%) and a lower number of patients as high risk (1\%) compared with SOAPP-R alone. ${ }^{16}$ However, based on other measures, including urine drug test (UDT), primary care physicians underestimated patients' potential for opioid misuse/abuse. ${ }^{16}$

Due to the lack of tools estimating misuse, abuse, and diversion in the pain patient population, the authors Setnik and Roland have developed a questionnaire assessing aberrant behaviors related to prescription opioid use, including tampering with products in order to alter the route of administration. The Self-Reported Misuse, Abuse, and Diversion Questionnaire (SR-MAD) includes questions that assess the presence and frequency of such behaviors, and furthermore, it assesses the motive behind each behavior in order to stratify them as either abuse or misuse. Definitions of misuse and abuse used in the instrument are consistent with those recently discussed by the Analgesic, Anesthetic, and Addiction Clinical Trials, Translations, Innovations, Opportunities, and Networks group. ${ }^{17}$ The current study utilized an early version of the SR-MAD that was developed to further characterize these behaviors in the primary care pain patient population.

\section{Objective}

This clinical study was designed to evaluate the success of converting opioid-experienced patients with chronic pain to a stable dose of an extended-release (ER) formulation of morphine sulfate surrounding sequestered naltrexone hydrochloride (MSN; EMBEDA ${ }^{\circledR}$; Pfizer Inc, New York, NY, USA) within a 6-week period, using a standardized conversion guide. One of the secondary objectives of the current study and the focus of this report was to evaluate the extent of and the risk for prescription opioid misuse, abuse, and diversion among patients with chronic pain, by comparing the investigator assessment of patient risk for these behaviors with patient self-reports of these activities. Two new questionnaires were developed specifically for this study and are in the process of validation. Because self-reports are dependent on responder honesty, the potential for substance abuse was also assessed through qualitative and quantitative UDT. Other secondary objectives of this study included assessing time to stable dose, number of titration steps, rescue medication use, adverse events, and conversion guide utility. The results of the objectives related to titration and conversion are published separately in this volume. ${ }^{18}$

\section{Patients and methods Study population}

Enrolled patients were men or women aged $\geq 21$ years with chronic ( $\geq 3$ months) moderate-to-severe pain who required an around-the-clock opioid for optimal analgesia. The patients had to be opioid-experienced, defined by taking a daily opioid dose for $\geq 30$ days prior to screening, excluding tramadol and/or ER morphine products. The patients had to be safely converted to a morphine dose of $\geq 20 \mathrm{mg} /$ day. To assess the ability to convert patients from various opioids, patients using the following opioids were recruited: transdermal fentanyl; immediate-release (IR) hydrocodone 
(including combinations with acetaminophen and ibuprofen); IR hydromorphone; IR oxycodone (including combinations with aspirin, acetaminophen, and ibuprofen); IR morphine; methadone; ER oxycodone; or ER oxymorphone.

Female patients could not be pregnant or lactating. If of childbearing age, females had to have a confirmed negative serum pregnancy test at baseline and practice appropriate methods of contraception throughout the study period. Those excluded from the study were patients with current evidence of opioid and/or alcohol abuse; those participating in and/or seeking treatment for opioid and/or alcohol abuse; and those with respiratory or gastrointestinal contraindications to opioid therapy (eg, significant respiratory depression, acute or severe bronchial asthma, or severe chronic obstructive pulmonary disease, suspected of having paralytic ileus).

\section{Study design}

This was an open-label, multicenter, primary care-based clinical study conducted in 157 centers, including 35 states, in the United States. The primary objective of this study was to assess the success of converting opioid-experienced patients with chronic pain to a stable dose of MSN using a standardized conversion guide. As one of the secondary objectives, patients were assessed for behaviors and risks related to prescription opioid misuse, abuse, and diversion by using specific questionnaires and assessments completed by the patient and/or the investigator. A certificate of confidentiality was used, and patients were informed that the investigators would not see the results during the study and would not use it against them. The study was conducted in three phases during which the following questionnaires and assessments were applied: screening phase (Visit 1), titration phase (Visits $2 \mathrm{a}-2 \mathrm{e}$ ), and maintenance phase/final visit (Visits 3-5). To convert to MSN, patients were titrated with MSN for up to 6 weeks to achieve a stable dose. To provide supplemental analgesia for breakthrough pain during titration, IR morphine $(<20 \%$ of the total daily dose of MSN per IR dose), ibuprofen (up to $400 \mathrm{mg} / \mathrm{dose}$, not to exceed $1,200 \mathrm{mg} /$ day), and acetaminophen (up to $1,000 \mathrm{mg} / \mathrm{dose}$, not to exceed 4,000 mg/day) were the only medications allowed as rescue at the discretion of the investigator. This study was conducted from August 27, 2010, to March 10, 2011, when the study was terminated early due to a voluntary sponsor recall of MSN because a prespecified stability requirement was not met during routine testing (ClinicalTrials.gov: NCT01179191).

The study was conducted in accordance with Good Clinical Practice requirements described in the current
International Conference on Harmonisation of Technical Requirements for Registration of Pharmaceuticals for Human Use Guidelines. All local regulatory requirements were followed, and all participants gave written informed consent prior to entering the study. The protocol and informed consent form were reviewed and approved by the Ethical and Independent Review Services West Coast Board (San Anselmo, CA). MSN is expected to be available again in 2015 .

\section{Risk assessments}

The risk assessment questionnaire is an investigator-completed assessment for each patient who evaluates a perceived risk level (low, moderate, or high) for prescription opioid misuse, abuse, and diversion. The questionnaire also documents the information sources used by the investigator to make each risk level assessment (Figure 1). The questionnaire was developed for this study and requires further validation. The risk assessment questionnaire provided definitions for low-, moderate-, and high-risk levels to ensure consistency in ratings among the investigators: low risk - little to no chance of developing problematic behaviors; moderate risk - possible chance of developing problematic behaviors; high risk - high chance of developing problematic behaviors. Additionally, the protocol definitions for misuse, abuse, and diversion are in line with those recently proposed by the ALERTT (Abuse Liability Evaluation for Research, Treatment, and Training) Working Group ${ }^{17}$ and were as follows: abuse, any use or the intentional self-administration of a medication for a nonmedical purpose such as altering one's state of consciousness, eg, getting high; misuse, the use of a medication (with therapeutic intent) other than as directed or as indicated, whether willful or unintentional, and whether harms results or not; and diversion, the transfer of legally obtainable drugs into illegal channels, including patients giving or selling their medication, pill mills (pain clinics that routinely prescribe and dispense large quantities of opioids outside the standards of normal medical practice), or the acquiring or obtaining of a controlled substance by an illegal method. The risk assessment questionnaire was completed by the investigator at Visit 1 .

The SR-MAD questionnaire (formerly the Patient Experience and Concerns with Prescription Opioids Questionnaire) is a nonvalidated instrument comprising several questions with multiple-choice options and several questions where patients rated their concerns with prescription opioids on an 11-point numeric rating scale $(0$, not at all; 10, extremely worried) (Figure 2). SR-MAD probes into various aberrant behaviors related to prescription opioids, 


\section{How would you describe this patient's potential risk for prescription opioid abuse?}

Abuse=any use or the intentional self-administration of a medication for a nonmedical purpose such as altering one's state of consciousness, eg, getting high.

\begin{tabular}{|l|l|l|}
\hline$\circ$ Low risk & $\circ$ Moderate risk & $\circ$ High risk \\
\hline
\end{tabular}

\section{How would you describe this patient's potential risk for prescription opioid misuse?}

Misuse=use of a medication (with therapeutic intent) other than as directed or as indicated.

\begin{tabular}{|l|l|l|}
\hline$\circ$ Low risk & $\circ$ Moderate risk & $\circ$ High risk \\
\hline
\end{tabular}

\section{How would you describe this patient's potential risk for prescription opioid diversion?}

Diversion=giving or selling their medication, or acquiring or obtaining of a controlled substance by an illegal method.

\begin{tabular}{|l|l|l|}
\hline$\circ$ Low risk & $\circ$ Moderate risk & $\circ$ High risk \\
\hline
\end{tabular}

\section{Please describe the type of information that you have relied on to make this assessment? (Please check all that apply.)}

\begin{tabular}{|l|l|}
\hline$\circ$ Past medical history & $\circ$ Prescription monitoring program \\
\hline$\circ$ History of treating/knowing the patient & $\circ$ Urine drug testing \\
\hline$\circ$ Interviewing the patient & $\circ$ Use of questionnaires to assess risk ${ }^{a}$ \\
\hline $\begin{array}{l}\text { Interviewing the patient's family member or } \\
\text { guardian }\end{array}$ & $\circ$ Assessment of patient's behavior \\
\hline$\circ$ Physical signs and symptoms & $\circ$ Pill counts \\
\hline
\end{tabular}

Figure I Risk assessment questionnaire.

Note: ${ }^{a}$ Opioid Risk Tool (ORT), Screener and Opioid Assessment for Patients with Pain (SOAPP), and Current Opioid Misuse Measure (COMM).

including overconsumption, tampering and administration by alternate routes, consumption with alcohol, and diversion of medication. SR-MAD was developed for this study and requires further validation. This questionnaire prompted patients to describe their current concerns and past/current behaviors related to prescription opioid misuse, abuse, and diversion, including pseudoaddiction (defined as drug-seeking behaviors related to the undertreatment of pain). ${ }^{19}$ This questionnaire was not reviewed by the investigators and/or the clinic staff but rather was provided to the patients upon the completion of Visit 1 . The patients were informed that their responses were confidential and would not be shared with their physician and/or the clinic staff. The patients were instructed to return the completed questionnaire to REGISTRAT MAPI (Boston, MA, USA; the contract research organization that managed the study) via mail.

COMM, a 17-item patient self-assessment tool, was also used in this study to monitor aberrant behavior in patients receiving opioid therapy. Aberrant behaviors were assessed 


\begin{tabular}{|c|c|c|c|c|c|c|c|c|c|c|c|c|c|c|c|}
\hline \multicolumn{2}{|r|}{ Question } & \multicolumn{14}{|c|}{ Response, $\mathbf{n}(\%)$} \\
\hline & & \multicolumn{10}{|c|}{ Not at all $=0$} & \multicolumn{4}{|c|}{ Extremely worried $=10$} \\
\hline & & 0 & \multicolumn{2}{|l|}{1} & 2 & 3 & 4 & \multicolumn{2}{|c|}{5} & 6 & 7 & \multicolumn{2}{|c|}{8} & 9 & 10 \\
\hline 1 & $\begin{array}{l}\text { How worried are you about getting } \\
\text { "addicted" or "hooked" to your opioid } \\
\text { medication? }\end{array}$ & $\begin{array}{c}171 \\
(31.8)\end{array}$ & $\begin{array}{c}47 \\
(8.8)\end{array}$ & \multicolumn{2}{|c|}{$\begin{array}{c}53 \\
(9.9)\end{array}$} & $\begin{array}{c}47 \\
(8.8)\end{array}$ & $\begin{array}{c}30 \\
(5.6)\end{array}$ & \multicolumn{2}{|c|}{$\begin{array}{c}53 \\
(9.9)\end{array}$} & $\begin{array}{c}28 \\
(5.2)\end{array}$ & $\begin{array}{l}33 \\
(6 .\end{array}$ & \multicolumn{2}{|c|}{$\begin{array}{c}31 \\
(5.8)\end{array}$} & $\begin{array}{c}11 \\
(2.0)\end{array}$ & $\begin{array}{c}33 \\
(6.1)\end{array}$ \\
\hline 2 & $\begin{array}{l}\text { Are you worried about having a hard } \\
\text { time stopping your opioid medication? }\end{array}$ & $\begin{array}{c}138 \\
(25.7)\end{array}$ & $\begin{array}{c}50 \\
(9.3)\end{array}$ & \multicolumn{2}{|c|}{$\begin{array}{c}67 \\
(12.5)\end{array}$} & $\begin{array}{c}45 \\
(8.4)\end{array}$ & $\begin{array}{c}20 \\
(3.7)\end{array}$ & \multicolumn{2}{|c|}{$\begin{array}{c}54 \\
(10.1)\end{array}$} & $\begin{array}{l}26 \\
(4.8)\end{array}$ & $\begin{array}{r}39 \\
(7.3\end{array}$ & & $\begin{array}{l}35 \\
(6.5)\end{array}$ & $\begin{array}{c}27 \\
(5.0)\end{array}$ & $\begin{array}{c}36 \\
(6.7)\end{array}$ \\
\hline 3 & How often (if ever) have you chewed or & $\mathrm{Nev}$ & & $\begin{array}{l}\text { Tried it } \\
\text { or tw }\end{array}$ & $\begin{array}{l}\text { once } \\
\text { ice }\end{array}$ & Fev & time & a year & & $\begin{array}{l}\text { w time } \\
\text { month }\end{array}$ & & $\begin{array}{l}\text { ew tim } \\
\text { week }\end{array}$ & $\begin{array}{l}\text { nes a } \\
\text { a }\end{array}$ & & Daily \\
\hline & & $476(8$ & 9.1) & $31(5$ & & & $5(0$. & & & $0(1.9)$ & & $7(1$. & & & $5(0.9)$ \\
\hline 4 & $\begin{array}{l}\text { If you have ever chewed or crushed your } \\
\text { opioid medication, why did you choose to } \\
\text { do so? }\end{array}$ & $\begin{array}{r}\text { Treat } n \\
\text { pain } \\
\text { bette }\end{array}$ & & $\begin{array}{l}\text { Treat a } \\
\text { new pain } \\
\text { condition }\end{array}$ & & $\begin{array}{l}\text { sleep } \\
\text { tter or } \\
\text { elax }\end{array}$ & & $\begin{array}{l}\text { lp me } \\
\text { llow my } \\
\text { lication }\end{array}$ & & $\begin{array}{l}\text { feel } \\
\text { asant } \\
\text { high }\end{array}$ & $\begin{array}{r}\text { To } \\
\text { le } \\
\text { depr } \\
\text { or ne }\end{array}$ & $\begin{array}{l}\text { feel } \\
\text { ss } \\
\text { essed } \\
\text { rvous }\end{array}$ & $\begin{array}{r}\text { To fe } \\
\text { mor } \\
\text { talkat } \\
\text { or } \\
\text { outgo }\end{array}$ & $\begin{array}{l}\text { feel } \\
\text { ore } \\
\text { ative } \\
\text { or } \\
\text { oing }\end{array}$ & $\begin{array}{c}\text { Other } \\
\text { (please } \\
\text { describe) }\end{array}$ \\
\hline & & $35(49$ & & $4(5.6)$ & 14 & (19.7) & & (22.5) & $3(4$ & & $6(8$ & & $2(2.8)$ & & $29(40.8)$ \\
\hline 5 & $\begin{array}{l}\text { How often (if ever) have you had to take } \\
\text { more of your opioid medication than }\end{array}$ & $\mathrm{Nev}$ & & $\begin{array}{r}\text { Need } \\
\text { once } \\
\text { twic }\end{array}$ & & & $\begin{array}{l}\text { ew tim } \\
\text { yea }\end{array}$ & & $\begin{array}{r}\text { Few } t \\
\mathrm{mc}\end{array}$ & $\begin{array}{l}\text { times } \\
\text { lonth }\end{array}$ & & $\begin{array}{l}\text { ew tim } \\
\text { wee }\end{array}$ & $\begin{array}{l}\text { nes a } \\
\text { ek }\end{array}$ & & Daily \\
\hline & & $212(4$ & 0.0) & $75(1$ & 4.2) & & $46(8$ & & 116 & $(21.9)$ & & $58(10$ & 0.9) & & $23(4.3)$ \\
\hline 6 & $\begin{array}{l}\text { If you have ever taken more of your } \\
\text { opioid medication than what was } \\
\text { prescribed, why did you choose to do }\end{array}$ & $\begin{array}{l}\text { Treat } \\
\text { pain be }\end{array}$ & & $\begin{array}{l}\text { Treat } \\
\text { new pa } \\
\text { conditi }\end{array}$ & & $\begin{array}{r}\text { To sl } \\
\text { bette } \\
\text { rela }\end{array}$ & & $\begin{array}{r}\text { To } \\
\text { pleas } \\
\text { hic }\end{array}$ & $\begin{array}{l}\text { o feel } \\
\text { asant or } \\
\text { high }\end{array}$ & & $\begin{array}{l}\text { To feel } \\
\text { less } \\
\text { pressed } \\
\text { nervous }\end{array}$ & & $\begin{array}{l}\text { To feel } \\
\text { more } \\
\text { lkative or } \\
\text { utgoing }\end{array}$ & & $\begin{array}{l}\text { Other } \\
\text { (please } \\
\text { describe) }\end{array}$ \\
\hline & & $274(8$ & & $42(13$ & & $48(1$ & 5.2) & & $(1.0)$ & & $6(5.1)$ & & $3(1.0)$ & & $44(14.0)$ \\
\hline 7 & $\begin{array}{l}\text { How often (if ever) have you ever tried to } \\
\text { snort, smoke, or inject your opioid pills or }\end{array}$ & $\mathrm{Nev}$ & & $\begin{array}{r}\text { Tried it } \\
\text { or tw }\end{array}$ & $\begin{array}{l}\text { once } \\
\text { vice }\end{array}$ & & yea & & $\begin{array}{r}\text { Few t } \\
\text { mo }\end{array}$ & $\begin{array}{l}\text { times } \\
\text { onth }\end{array}$ & & $\begin{array}{l}\text { ew tim } \\
\text { wee }\end{array}$ & $\begin{array}{l}\text { nes a } \\
\text { ek }\end{array}$ & & Daily \\
\hline & tablets? & $523(c$ & 8.1) & $7(1$ & & & $0(0$. & & & $(0.4)$ & & $0(0$. & & & $1(0.2)$ \\
\hline 8 & $\begin{array}{l}\text { If you have ever tried to snort, smoke, or } \\
\text { inject your opioid pills or tablets, why did } \\
\text { you choose to do so? }\end{array}$ & $\begin{array}{l}\text { Treat } \\
\text { pain be }\end{array}$ & & $\begin{array}{l}\text { Treat } \\
\text { new pa } \\
\text { conditic }\end{array}$ & & $\begin{array}{l}\text { To sl } \\
\text { bette } \\
\text { rela }\end{array}$ & & $\begin{array}{r}\text { To } \\
\text { pleas } \\
\text { hic }\end{array}$ & $\begin{array}{l}\text { feel } \\
\text { sant or } \\
\text { high }\end{array}$ & & $\begin{array}{l}\text { To feel } \\
\text { less } \\
\text { pressed } \\
\text { nervous }\end{array}$ & & $\begin{array}{l}\text { To feel } \\
\text { more } \\
\text { Ikative or } \\
\text { utgoing }\end{array}$ & & $\begin{array}{l}\text { Other } \\
\text { (please } \\
\text { describe) }\end{array}$ \\
\hline & & $10(27$ & & $1(2.7$ & & $2(5$ & & & (5.4) & & $2(5.4)$ & & $2(5.4)$ & & $28(75.7)$ \\
\hline 9 & $\begin{array}{l}\text { How often (if ever) do you drink alcohol } \\
\text { while on your opioid medication? }\end{array}$ & $\mathrm{Nev}$ & & $\begin{array}{r}\text { Tried it } \\
\text { or tw }\end{array}$ & $\begin{array}{l}\text { once } \\
\text { ice }\end{array}$ & & $\begin{array}{l}\text { w tim } \\
\text { yea }\end{array}$ & & $\begin{array}{r}\text { Few } t \\
\mathrm{mo}\end{array}$ & $\begin{array}{l}\text { times } \\
\text { onth }\end{array}$ & & $\begin{array}{l}\text { ew tim } \\
\text { week }\end{array}$ & $\begin{array}{l}\operatorname{mes}_{\mathrm{k}} \mathrm{a} \\
\mathrm{k}\end{array}$ & & Daily \\
\hline & & $391(7$ & 3.2) & $32(6$ & & & $0(9$. & & & (6.6) & & $19(3$ & 3.6) & & $7(1.3)$ \\
\hline 10 & $\begin{array}{l}\text { If you have had alcohol while on your } \\
\text { opioid medication, why did you choose to } \\
\text { do so? }\end{array}$ & $\begin{array}{r}\text { Treat } n \\
\text { pain } \\
\text { bette }\end{array}$ & & $\begin{array}{l}\text { Treat a } \\
\text { new pain } \\
\text { condition }\end{array}$ & & $\begin{array}{l}\text { sleep } \\
\text { ter or } \\
\text { elax }\end{array}$ & $\begin{array}{r}\text { I er } \\
\text { d } \\
\text { occas }\end{array}$ & $\begin{array}{l}\text { oy a } \\
\text { nk } \\
\text { ionally }\end{array}$ & $\begin{array}{l}\text { To fe } \\
\text { pleasa } \\
\text { or hig }\end{array}$ & & $\begin{array}{l}\text { To fe } \\
\text { less } \\
\text { depress } \\
\text { or } \\
\text { nervou }\end{array}$ & & $\begin{array}{l}\text { To feel } \\
\text { more } \\
\text { talkative } \\
\text { or } \\
\text { outgoing }\end{array}$ & & $\begin{array}{l}\text { Other } \\
\text { (please } \\
\text { describe) }\end{array}$ \\
\hline & & $10(5.9$ & & $1(0.6)$ & 21( & 12.4) & 91( & 3.5) & $3(1.8)$ & & $4(2.4)$ & & $2(1.2)$ & & $65(38.2)$ \\
\hline & Have you ever had to visit more than 1 & & Neve & & $\mathrm{Hac}$ & to on & e or $t$ & & & ometin & imes & & & Often & \\
\hline & your opioid medication? & & $38(92$ & & & 26( & 4.9) & & & $12(2$ & & & & $3(0.6)$ & \\
\hline 12 & $\begin{array}{l}\text { If you ever had to visit more than } 1 \\
\text { doctor at the same time to get enough of } \\
\text { your opioid medication, why did choose }\end{array}$ & $\begin{array}{r}\text { Treat } \\
\text { pain be }\end{array}$ & & $\begin{array}{r}\text { Prev } \\
\text { withdra }\end{array}$ & $\begin{array}{l}\text { jent } \\
\text { awal }\end{array}$ & & $\begin{array}{l}\text { as afr } \\
\text { my d } \\
\text { or mo }\end{array}$ & $\begin{array}{l}\text { id to } \\
\text { ctor }\end{array}$ & $\begin{array}{r}\text { To } \\
\text { pleas } \\
\text { hig }\end{array}$ & $\begin{array}{l}\text { feel } \\
\text { sant o } \\
\text { gh }\end{array}$ & & $\begin{array}{l}\text { My do } \\
\text { would } \\
\text { prescl } \\
\text { more }\end{array}$ & $\begin{array}{l}\text { octor } \\
\text { d not } \\
\text { cribe } \\
\text { e }\end{array}$ & $\begin{array}{r}\text { Other } \\
\text { des }\end{array}$ & $\begin{array}{l}\text { er (please } \\
\text { scribe) }\end{array}$ \\
\hline & & $26(4$ & & $6(9$ & & & $2(19$ & & & (1.6) & & $11(1 \varepsilon$ & 18.0) & & $4(39.3)$ \\
\hline & Have you ever helped someone else & & & & No & & & & & & & $\mathrm{Ye}$ & es & & \\
\hline 13 & some of your opioid medication? & & & 491 & $(93.3$ & & & & & & & $35(6$ & (6.7) & & \\
\hline
\end{tabular}

Figure 2 (Continued) 


\begin{tabular}{|c|c|c|c|c|c|}
\hline \multirow{2}{*}{14} & \multirow{2}{*}{$\begin{array}{l}\text { If you answered yes to question } 13, \text { how } \\
\text { many times have you ever given away } \\
\text { your opioid medication? }\end{array}$} & 1 time & $2-5$ times & $6-10$ times & More than 10 times \\
\hline & & $5(14.3)$ & $24(68.6)$ & $3(8.6)$ & $3(8.6)$ \\
\hline & & \multicolumn{2}{|c|}{ No } & \multicolumn{2}{|c|}{ Yes } \\
\hline 15 & $\begin{array}{l}\text { Have you ever had to get your opioid } \\
\text { medication from someone who was not a } \\
\text { doctor because you didn't have enough? }\end{array}$ & \multicolumn{2}{|c|}{$494(92.0)$} & \multicolumn{2}{|c|}{$43(8.0)$} \\
\hline 16 & $\begin{array}{l}\text { Do you keep your opioid medication } \\
\text { hidden or locked away? }\end{array}$ & \multicolumn{2}{|c|}{$162(30.3)$} & \multicolumn{2}{|c|}{$373(69.7)$} \\
\hline \multirow{2}{*}{17} & \multirow{2}{*}{$\begin{array}{l}\text { Have you ever suspected that someone } \\
\text { else may be taking your medication } \\
\text { without asking you? }\end{array}$} & \multicolumn{2}{|c|}{ No } & \multicolumn{2}{|c|}{ Yes } \\
\hline & & \multicolumn{2}{|c|}{$464(86.7)$} & \multicolumn{2}{|c|}{$71(13.3)$} \\
\hline \multirow{2}{*}{18} & \multirow{2}{*}{$\begin{array}{l}\text { If you answered yes to question } 17, \text { how } \\
\text { many times have you ever suspected } \\
\text { this? (one answer is missing) }\end{array}$} & Once & A few times & Sometimes & All the time \\
\hline & & 30 (42.9) & $29(41.4)$ & $8(11.4)$ & $3(4.3)$ \\
\hline
\end{tabular}

Figure 2 Patients' responses on the self-reported misuse, abuse, and diversion questionnaire.

using a 5 -point scale ( 0 , never; 4 , very often), and a total score was calculated (maximum possible total score is 68). A COMM score $\geq 9$ indicated the presence of aberrant behaviors. ${ }^{14}$ This low cutoff score, recommended by the developers of COMM, was intended to overidentify misuse, as it is more important to identify patients who have only a possibility of misusing their medications than to fail to identify those who are actually misusing their medication. Thus, it is possible that COMM will result in false positives - patients identified as misusing their medication when they were not and may only have the potential to do so. The patients received COMM at Visit 2 and were asked to return the completed questionnaire to REGISTRAT MAPI via mail. This measure has been validated for use in patients with chronic pain.

Urine samples collected at Visits 1 and 3 (or the following visit) were screened qualitatively at a laboratory site using immunoassay techniques (or equivalent) for the following classes/types of drugs: opioids, barbiturates, benzodiazepines, amphetamines, ecstasy (3,4-methylenedioxymethamphetamine [MDMA]), cocaine, phencyclidine (PCP), and marijuana (tetrahydrocannabinol [THC]). If qualitative UDT results were positive, the appropriate quantitative confirmatory testing was performed using gas chromatography, high-pressure liquid chromatography, or the equivalent for the following analytes: morphine, oxycodone, oxymorphone, hydrocodone, hydromorphone, fentanyl, methadone, benzodiazepines, amphetamines, cocaine, THC, PCP, MDMA, and methylendioxyamphetamine (MDA). Both qualitative and the appropriate quantitative test results had to be positive for a UDT result to be identified as positive. The three categories of abnormal UDT results were:

1. Positive for illicit substances: if they were positive for THC, cocaine, PCP, MDMA, or MDA, a patient's UDT results were considered positive for illicit substances with the exception that if the patient's medication history indicated legitimate cannabinoid use, positive results for THC at Visit 1 were not counted as abnormal. Positive THC results at Visit 3 were considered abnormal for all patients.

2. Positive for unaccounted opioids: the frequency of patients who were positive for unaccounted opioids could not be determined for all prior opioid types at Visit 1 because some of the prior opioid types could not be distinguished uniquely through confirmatory analytes. Therefore, the frequency of patients positive for unaccounted opioids was calculated at Visit 3 only. Unaccounted opioids at Visit 3 were defined as any opioid (or corresponding metabolite) other than morphine.

3. Negative for expected opioid: at Visit 1, a patient's UDT results were considered negative for expected opioid if they were negative for all of the following: opiates, methadone, oxycodone, and fentanyl. These opioids were included regardless of a patient's prior opioid type classification because patients could be taking more than one prescribed opioid type at Visit 1. Prior opioid type was assigned to each patient by the investigator, and the analyses did not crossverify prior opioid type classification against medication records. At Visit 3, a patient's UDT results were considered negative for expected opioid if they were negative for morphine (the opioid component of MSN). 




Figure 3 Patient disposition.

Notes: a One patient completed Visit 3 but did not have Visit 5 or officially discontinue. Therefore, he is not counted as discontinuing the study, although he did not complete the maintenance phase; ${ }^{b}$ more than one subcategory could be indicated.

Abbreviation: $\mathrm{AE}$, adverse event.

\section{Statistical analyses}

The investigators' responses on the risk assessment questionnaire were summarized descriptively. The patients were classified as low, moderate, or high risk separately for misuse, abuse, and diversion. Patients' reports of prior/current concerns with prescription opioid misuse, abuse, and diversion were summarized directly from SR-MAD. The investigator risk assessment for misuse, abuse, and diversion was crosstabulated with COMM scores and abnormal UDT results.

\section{Results}

\section{Patient demographics}

A total of 687 patients provided informed consent, 684 patients completed Visit 1 and filled a prescription for MSN, and 234 patients completed the study. The patient disposition is presented in Figure 3. The 684 patients who completed Visit 1 comprised 55.3\% females, 83.3\% white, and with a mean (standard deviation [SD]) age of 51.77 (12.34) years (range, 21-90 years). As would be expected for this population, most patients $(92.1 \%)$ had a significant medical history based on the patient's report at baseline; the most frequently affected body systems were musculoskeletal (72.8\%), psychiatric (51.7\%), cardiovascular (49.4\%), endocrine/metabolic (44.5\%), and gastrointestinal (41.2\%). About half of the patients (55.1\%) had musculoskeletal pain as their primary pain classification; the next most frequent categories were arthritis pain (23.9\%) and nerve-related pain (10.7\%). Most patients (95.1\%) had been experiencing their primary current pain for more than 1 year, $57.4 \%$ for more than 5 years, and $32.1 \%$ for more than 10 years.

Overall, 27.2\% of patients reported current alcohol use and $27.8 \%$ reported alcohol use only in the past; of the past users, most (82.6\%) denied problems with alcohol use. About one-third of patients (33.5\%) indicated that they had never used tobacco, and $43.5 \%$ reported current tobacco use. Most patients (89.1\%) denied a history of nonmedical drug use or abuse. The most frequently reported past drugs of abuse were marijuana ( $74.6 \%$ of past users) and cocaine $(36.6 \%)$, with all other drugs reported by $<10 \%$ of past users.

\section{Risk assessment outcome}

\section{Investigator risk assessment questionnaire}

Of the 684 patients who completed Visit 1, 683 patients were assessed by the investigator for risk for misuse and abuse and 682 were assessed for risk for diversion. The percentage of 
patients in each risk category (low, moderate, or high) for misuse, abuse, and diversion assigned through the investigator risk assessment questionnaire are presented in Figure 4. Overall, the investigators assessed most patients as having low risk for misuse (84.2\%), abuse (89.3\%), and diversion (94.3\%). Few patients were considered at high risk for these behaviors $(1.6 \%, 1.8 \%$, and $1.0 \%$, respectively). The most frequent sources of information used by the investigators to assess the patients' risk level (multiple sources could be used for a given patient) were medical history $(84.9 \%)$, patient interview $(81.7 \%)$, and history of treating/knowing the patient $(67.8 \%)$. Less frequently reported sources of information were questionnaires $(21.5 \%)$, pill counts $(11.9 \%)$, and interviewing the patient's family $(7.3 \%)$.

\section{SR-MAD questionnaire}

A total of 537 (78.5\%) patients returned the SR-MAD. Patients' responses on SR-MAD are presented in Figure 2. Of the 537 patients who returned the SR-MAD, 60.0\% reported taking more opioid medication than prescribed, $26.8 \%$ indicated that they had consumed alcohol while receiving opioid medication, $10.9 \%$ reported chewing or crushing opioid medication, $8.0 \%$ reported getting their opioid medication from someone who was not a doctor, $7.8 \%$ reported visiting more than one doctor to get enough opioid medication, and 1.9\% reported snorting, smoking, or injecting opioid medication. The reasons cited for these behaviors and responses to other questions are presented in Figure 2.

\section{Current opioid misuse measure}

Of the $535(78.2 \%)$ patients who completed the COMM, a total of $217(40.6 \%)$ patients were classified as having

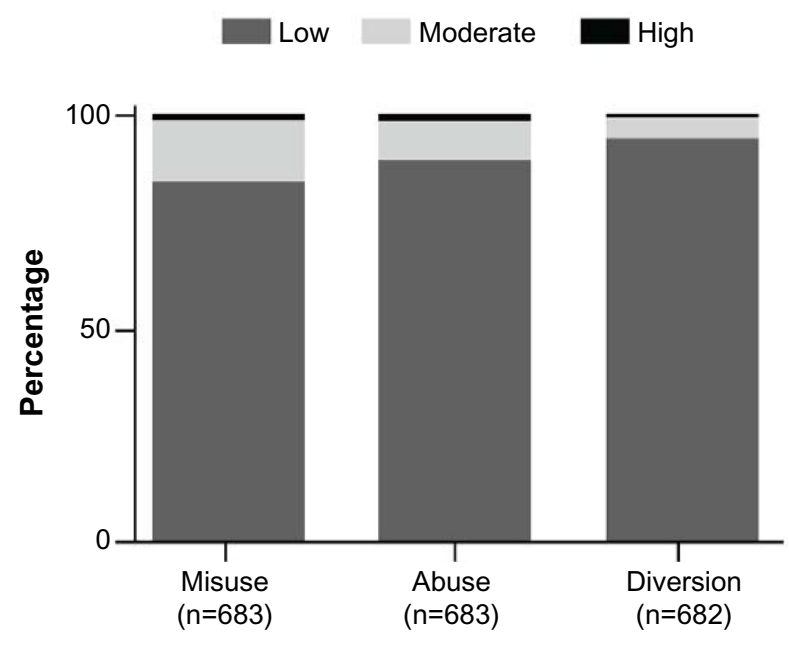

Figure 4 Risk levels based on the investigator risk assessment questionnaire reported at baseline. aberrant behaviors (COMM score $\geq 9$ ), the median (range) COMM score was 7 (0-51), and the mean (SD) COMM score was close to the cutoff value at 8.7 (7.3).

\section{Cross-tabulation of COMM score versus investigator} risk assessment

The frequencies of patients with aberrant behaviors (COMM score $\geq 9$ ) and COMM score values were crosstabulated versus the investigator risk assessment levels for misuse, abuse, and diversion. In general, mean and median COMM scores were greater in patients with high- and moderate-risk assessments than in patients with low-risk assessments (Table 1). However, the sample size decreased noticeably as risk level increased (Table 1).

\section{UDT results}

Percentages of patients with positive UDT results at Visits 1 and 3 are presented in Figure 5. At Visit 1, 23.4\% (160 of 684) of patients had at least one abnormal UDT result. Of the $7.5 \%$ (51 of 684) of patients who had at least one positive result for an illicit substance at Visit 1, 6.1\% (42 of 684) of patients had a confirmed positive test result for THC, and 1.8\% (12 of 684) of patients had a confirmed positive test result for cocaine (Figure 5). A positive test result for THC at Visit 1 was not considered abnormal if the patient had marinol or medical marijuana recorded as an adjunctive pain medication. No patients had positive results for PCP or illicit amphetamine (MDMA or MDA). At Visit 1, 17.8\% (122 of 684) of patients tested negative for expected opioid use.

A total of 351 patients completed Visit 3, and 28.8\% (101 of 351) of patients had at least one abnormal UDT result. Of

Table I Crosstabulation of COMM score versus investigator risk assessment for misuse, abuse, and diversion

\begin{tabular}{clll}
\hline Risk category & \multicolumn{3}{l}{ COMM score by investigator risk } \\
\cline { 2 - 4 } & \multicolumn{1}{l}{ Assessment level } & High \\
\cline { 2 - 4 } & Low & 75 & 7 \\
\hline Misuse, $\mathrm{n}$ & 453 & $10.75(8.26)$ & $13.86(7.40)$ \\
Mean (SD) & $8.26(7.09)$ & 9.00 & 11.00 \\
Median & 6.00 & $0.0,38.0$ & $5.0,25.0$ \\
Min, max & $0.0,51.0$ & 48 & 9 \\
Abuse, $\mathrm{n}$ & 478 & $1 \mathrm{I} .3 \mathrm{I}(9.86)$ & $11.00(8.25)$ \\
Mean (SD) & $8.37(6.97)$ & 8.00 & 9.00 \\
Median & 7.00 & $0.0,51.0$ & $2.0,25.0$ \\
Min, max & $0.0,42.0$ & 23 & 4 \\
Diversion, $\mathrm{n}$ & 507 & $9.43(8.64)$ & $12.75(9.18)$ \\
Mean (SD) & $8.62(7.27)$ & 7.00 & 13.00 \\
Median & 7.00 & $0.0,38.0$ & $3.0,22.0$ \\
Min, max & $0.0,51.0$ &
\end{tabular}

Abbreviations: COMM, Current Opioid Misuse Measure; SD, standard deviation. 


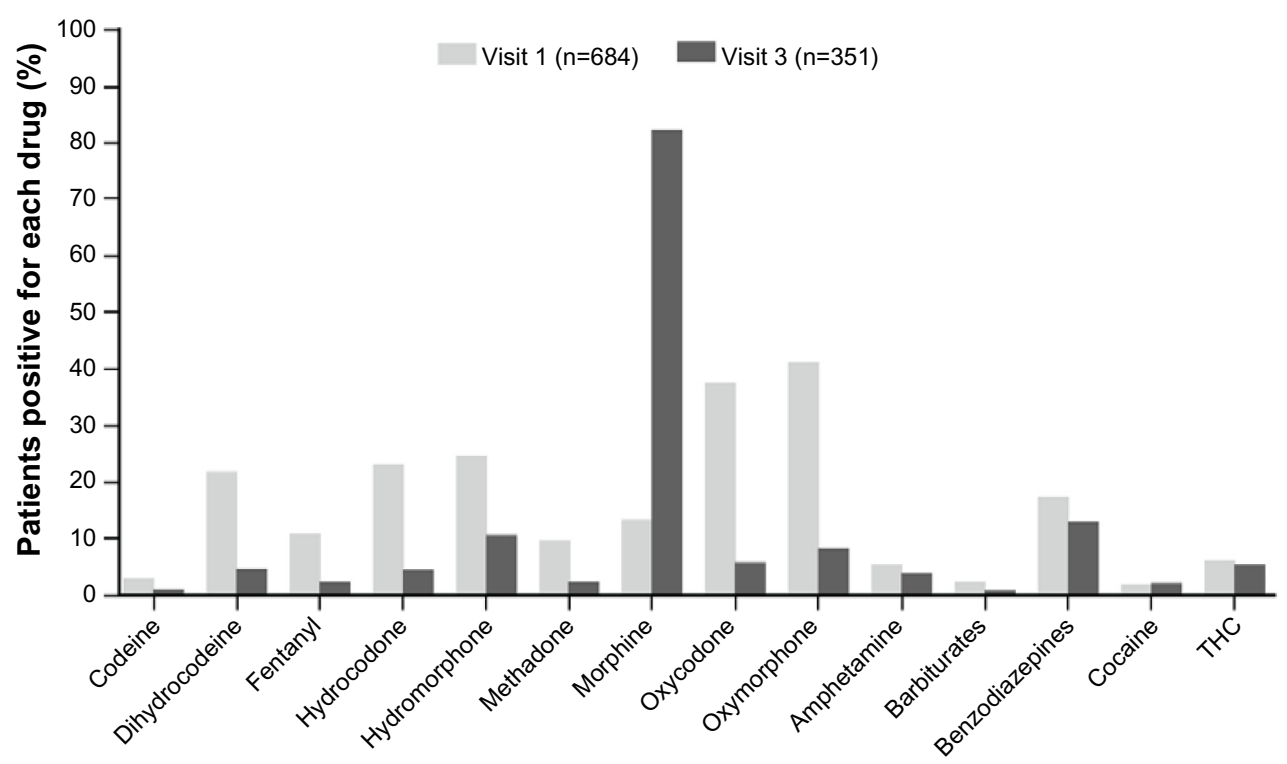

Figure 5 Positive urine drug test results at Visits I and 3.a,

Notes: abnormal results confirmed by quantitative testing; ${ }^{b}$ no patients had positive results for phencyclidine or illicit amphetamine at either Visit I or Visit 3. Positive amphetamine results may be attributed to legitimate prescription use of amphetamine analogs.

Abbreviation: THC, tetrahydrocannabinol.

the $6.8 \%$ (24 of 351$)$ of patients who had at least one positive result for an illicit substance at Visit 3, 5.4\% (19 of 351) of patients had a confirmed positive test result for THC, and $2.0 \%$ (seven of 351 ) of patients had a confirmed positive test result for cocaine (Figure 5). No patients had positive results for PCP or illicit amphetamine (MDMA or MDA). At Visit 3, $24.2 \%$ ( 85 of 351 ) of patients had at least one positive result for an unaccounted opioid: $19.0 \%$ (eight of 42) of patients whose prior opioid type was fentanyl had a positive UDT result for fentanyl; $10.1 \%$ (ten of 99) of patients whose prior opioid type was hydrocodone had a positive UDT result for dihydrocodeine and 9.1\% (nine of 99) had a positive UDT result for hydrocodone; $15.4 \%$ (four of 26) of patients whose prior opioid type was methadone had a positive UDT result for methadone; $14.3 \%$ (eleven of 77 ) of patients whose prior opioid type was IR oxycodone had a positive UDT result for oxycodone and $15.6 \%$ (12 of 77) had a positive UDT result for oxymorphone; and $28.6 \%$ (four of 14) of patients whose prior opioid type was ER oxymorphone had a positive UDT result for oxymorphone. At Visit 3, 3.1\% (11 of 351) of patients tested negative for expected opioid use.

Overall, 33.8\% (231 of 684) of patients had at least one abnormal UDT result at either Visit 1 or Visit 3: 9.4\% (64 of 684) of patients had at least one positive result for an illicit substance, $7.6 \%$ (52 of 684) of patients had a confirmed positive test result for THC, and 2.2\% (15 of 684) of patients had a confirmed positive test result for cocaine. No patients had positive results for PCP or illicit amphetamine (MDMA or
MDA). At Visit 1 or Visit 3, 18.7\% (128 of 684) of patients had negative test results for expected opioid.

\section{Crosstabulation of investigator risk assessment versus UDT results}

Exploratory crosstabulations were performed for UDT results compared with the investigator risk assessments (Table 2). Of the patients who were assigned as low risk for abuse and diversion by the investigator, $6.6 \%$ and $6.8 \%$, respectively, tested positive for illicit substance use by UDT at both Visit 1 and Visit 3. Similarly, $6.4 \%$ and $6.0 \%$ of the patients who were assigned as low risk for misuse by the investigator tested positive for illicit substance use by UDT at Visits 1 and 3, respectively (Table 2). The frequency of illicit UDT results at Visit 1 appeared to increase with increasing risk level assigned by the investigator for abuse and misuse. The presence of unaccounted opioid at Visit 3 appeared to be independent of risk level for all investigator risk categories. As noted above, about one-fourth of patients at Visit 3 (24.2\%) had at least one positive result for an unaccounted opioid. The absence of expected opioid at Visit 1 appeared to be more frequent in patients with moderate-to-high investigator risk for diversion (Table 2).

\section{Discussion}

Before considering long-term opioid therapy for patients with chronic pain, it is important to identify patient characteristics that might place them at high risk for opioid misuse, abuse, 
Table 2 Abnormal UDT results reported versus investigator risk assessment for misuse, abuse, and diversion

\begin{tabular}{|c|c|c|c|c|}
\hline \multirow[b]{2}{*}{ Misuse } & \multicolumn{4}{|c|}{ Investigator risk assessment level } \\
\hline & Low $(\mathbf{N}=575)$ & Moderate $(\mathrm{N}=97)$ & High ( $\mathbf{N}=\mathrm{II})$ & Total $\left(\mathbf{N}=684^{a}\right)$ \\
\hline Patients with $\geq \mathrm{I}$ abnormal UDT result at Visit $\mathrm{I}^{\mathrm{b}}, \mathrm{n}(\%)$ & $128(22.3)$ & $26(26.8)$ & $5(45.5)$ & $160(23.4)$ \\
\hline Patients positive for illicit substance & $37(6.4)$ & II (II.3) & $3(27.3)$ & $51(7.5)$ \\
\hline Patients negative for expected opioid use & $101(17.6)$ & $18(18.6)$ & $2(18.2)$ & $122(17.8)$ \\
\hline Patients who completed Visit $3, \mathrm{n}$ & 301 & 45 & 5 & 351 \\
\hline Patients with $\geq$ I abnormal UDT result at Visit $3^{c}, \mathrm{n}(\%)$ & $83(27.6)$ & $16(35.6)$ & $2(40.0)$ & I0I (28.8) \\
\hline Patients positive for illicit substance & $18(6.0)$ & $5(11.1)$ & I (20.0) & $24(6.8)$ \\
\hline Patients positive for unaccounted opioid & $70(23.3)$ & $14(3 \mid .1)$ & I (20.0) & $85(24.2)$ \\
\hline Patients negative for expected opioid use & II (3.7) & $0(0.0)$ & $0(0.0)$ & II (3.I) \\
\hline Abuse & Low $(\mathrm{N}=610)$ & Moderate $(\mathrm{N}=6 \mathrm{I})$ & High $(\mathbf{N}=12)$ & Total $\left(\mathrm{N}=684^{\mathrm{a}}\right)$ \\
\hline Patients with $\geq \mathrm{I}$ abnormal UDT result at Visit $\mathrm{I}^{\mathrm{b}}, \mathrm{n}(\%)$ & $136(22.3)$ & $19(31.1)$ & $4(33.3)$ & $160(23.4)$ \\
\hline Patients positive for illicit substance & $40(6.6)$ & $9(14.8)$ & $2(16.7)$ & $51(7.5)$ \\
\hline Patients negative for expected opioid use & $107(17.5)$ & $12(19.7)$ & $2(16.7)$ & $122(17.8)$ \\
\hline Patients who completed Visit 3, n & 319 & 26 & 6 & 351 \\
\hline Patients with $\geq$ I abnormal UDT result at Visit $3^{c}, \mathrm{n}(\%)$ & $92(28.8)$ & $7(26.9)$ & $2(33.3)$ & IOI (28.8) \\
\hline Patients positive for illicit substance & $21(6.6)$ & $3(11.5)$ & $0(0.0)$ & $24(6.8)$ \\
\hline Patients positive for unaccounted opioid & $78(24.5)$ & $5(19.2)$ & $2(33.3)$ & $85(24.2)$ \\
\hline Patients negative for expected opioid use & II (3.4) & $0(0.0)$ & $0(0.0)$ & II (3.I) \\
\hline Diversion & Low $(\mathrm{N}=643)$ & Moderate $(\mathrm{N}=32)$ & High $(\mathbf{N}=7)$ & Total $\left(\mathrm{N}=684^{\mathrm{a}}\right)$ \\
\hline Patients with $\geq \mathrm{I}$ abnormal UDT result at Visit $\mathrm{I}^{\mathrm{b}}, \mathrm{n}(\%)$ & $143(22.2)$ & $13(40.6)$ & $3(42.9)$ & $160(23.4)$ \\
\hline Patients positive for illicit substance & $44(6.8)$ & $6(18.8)$ & I (I4.3) & $51(7.5)$ \\
\hline Patients negative for expected opioid use & $111(17.3)$ & $8(25.0)$ & $2(28.6)$ & $122(17.8)$ \\
\hline Patients who completed Visit 3, n & 336 & 11 & 3 & 351 \\
\hline Patients with $\geq$ I abnormal UDT result at Visit $3^{c}, \mathrm{n}(\%)$ & $97(28.9)$ & $4(36.4)$ & $0(0.0)$ & I0I (28.8) \\
\hline Patients positive for illicit substance & $23(6.8)$ & I (9.I) & $0(0.0)$ & $24(6.8)$ \\
\hline Patients positive for unaccounted opioid & $82(24.4)$ & $3(27.3)$ & $0(0.0)$ & $85(24.2)$ \\
\hline Patients negative for expected opioid use & II (3.3) & $0(0.0)$ & $0(0.0)$ & II (3.I) \\
\hline
\end{tabular}

Notes: ancludes patients who were missing assignment of risk level, I for abuse, I for misuse, and 2 for diversion; ${ }^{b}$ percentage is calculated using the number of patients in each risk category (low, moderate, high, total) as the denominator; 'percentage is calculated using the number of patients who completed Visit 3 within each risk category (low, moderate, high, total) as the denominator.

Abbreviation: UDT, urine drug test.

and diversion. The present study describes the extent of and the risk for prescription opioid misuse, abuse, and diversion among patients with chronic pain based on two nonvalidated questionnaires that were developed specifically for this study: one was completed by the investigator (investigator risk assessment questionnaire) and the other by the patient (SR-MAD). The results from these two questionnaires were crosstabulated and compared with results from the validated COMM and the objective UDT.

SR-MAD evaluates the past/current extent of prescription opioid misuse, abuse, and diversion among the pain patient population. Unlike currently available questionnaires that are limited to assessing misuse or addiction, ${ }^{11-13}$ SR-MAD probes into various aberrant behaviors related to prescription opioids, including overconsumption, tampering and administration by alternate routes, consumption with alcohol, and diversion of medication. Another unique feature of SR-MAD is that it attempts to differentiate what behaviors may be attributed to abuse versus misuse of prescription opioids by assessing the motive underlying the behavior. The most commonly reported aberrant behavior reported by the majority of patients was overconsumption of prescription opioid medication. Overconsumption was reported to occur on at least a monthly basis by about one-third of these patients. Overconsumption was also the most commonly reported aberrant behavior among patients discharged from the ED with an opioid prescription ( 33 of $36 ; 92 \%$ ) at either 3 or 30 days after their ED visit. ${ }^{20}$ The second most prevalent aberrant behavior was consuming alcohol while receiving opioid medication, followed by inappropriate use of the opioid medication by either crushing or chewing. The least common aberrant behavior was administration by inhalation, insufflation, or injection. Potential doctor shopping was also reported in this population with $\sim 1$ of 10 patients having reported visiting more than one doctor at the same time to obtain opioid medication. Data from the California Prescription Drug Monitoring Program show that opioid use and doctor shopping increased substantially from 1999 
to $2007 .{ }^{21}$ Furthermore, having more than four prescribers per year was associated with increased risk for death related to prescription opioid overdose. ${ }^{22}$ The SR-MAD is able to identify doctor shoppers and may assist in controlling the risk of opioid overdose. Overall, these self-reports suggest that a subset of patients with chronic pain have engaged in aberrant behaviors related to prescription opioid medication. Of note, the SR-MAD is not intended to be an in-clinic instrument for physician's use since the very element of anonymity is essential to elicit honest responding. It is meant as a tool for research purposes only, where these behaviors can be measured in an anonymous fashion.

The investigator assessments of risk related to prescription opioid misuse, abuse, and diversion indicated that the majority of patients assessed were at low risk (having little or no chance) for developing these behaviors ( $>80 \%$ per category). These results are consistent with the intended study population comprising patients with chronic pain who were opioid-experienced (taking a daily opioid dose for $\geq 30$ days prior to Visit 1) and had no history or current signs/symptoms of opioid and/or alcohol abuse. COMM results, however, identified $\sim 41 \%$ of the patients who completed this test as having aberrant drug-related behaviors associated with misuse of opioid medications. One possible explanation for the higher percentage of patients with aberrant behavior identified by COMM is that some patients may have been falsely identified as misusing their medication because of the low cutoff score (COMM $\geq 9$ ) set for this test. ${ }^{14}$ Crosstabulation analysis showed that mean COMM scores tended to increase with investigator risk level, suggesting some correlation between these assessments. Of note, the SDs (6.97-7.27) of COMM scores imply that there were likely a substantial number of patients who had COMM scores $>9$ but were deemed as low risk by the investigator.

Only a few patients $(1.0 \%-1.8 \%)$ were classified by the investigators as having high risk for misuse, abuse, and diversion; however, a considerable number of patients $(6.0 \%-6.8 \%)$ who were deemed by the investigator as low risk for these behaviors had at least one positive UDT result for an illicit substance (cocaine and/or marijuana) at either Visit 1 or Visit 3. Similarly, a previous study showed that only a small number of patients $(4 \%)$ were considered by the investigator as exhibiting aberrant drug-related behaviors, whereas $15 \%$ of the patients had a positive UDT result for an illicit drug (cocaine, marijuana, PCP, and/or ecstasy). ${ }^{16}$ The results from both studies indicate a tendency for investigators to underestimate their patients' risk for engaging in drug-related aberrant behaviors.

To assess patients' risk level for misuse, abuse, or diversion, the investigators in the current study relied on medical history, interviewing the patient, and history of treating/ knowing the patient. The use of risk assessment tools similar to those presented in this study may improve the ability of primary care physicians to assess patients' risk for these behaviors. The investigator risk assessment questionnaire provides the investigator with definitions for level of risk as well as definitions for misuse, abuse, and diversion to allow prediction of the specific aberrant opioid-related behaviors. Specific definitions were provided to ensure consistency of terminology for all the investigators, which is currently lacking in clinical trials to date. ${ }^{23}$ Discriminating between patients who have the potential to misuse prescription opioids in an attempt to ease their pain from those who have the potential to abuse prescription opioids is important for both pain management and controlling drug abuse. Furthermore, our results indicate that investigators used questionnaires with $21.5 \%$ of patients to assess risk, and yet, only few were assessed as having high risk to misuse $(1.6 \%)$ or abuse $(1.8 \%)$. This suggests that the investigators may require additional education/ training on how to interpret the results of the questionnaires to assess patient's risk.

Results of UDT were intended to supplement the investigator risk assessment by providing objective information on opioid and other drug use during the study. These results indicated that a small proportion of patients $(9.4 \%)$ had at least one positive result for an illicit substance at either Visit 1 or Visit 3. The percentage of patients with a confirmed positive test result for cocaine or THC did not differ substantively between Visit 1 (1.8\% and $6.1 \%$, respectively) and Visit $3(2.0 \%$ and $5.4 \%$, respectively), suggesting no relationship between successful titration and illicit substance use. The small percentages of patients with a positive result for an illicit substance found in this study are different from those reported in the previous study in patients with pain. ${ }^{16}$ In that trial, a higher percentage of patients tested positive for cocaine $(18 \%)$ and $\mathrm{THC}(22 \%)$ at any time during the study. ${ }^{16}$ One possible explanation for these differences is that the study with higher positive rates used qualitative UDT, which were not confirmed by more rigorous laboratory testing, and could yield false positive results. Alternatively, the differences between the studies could result from different inclusion/exclusion criteria (eg, history of substance abuse). 
Several limitations need to be taken into account when considering the results from the present study. First, the early termination of the study resulted in the enrollment of only approximately half of the anticipated number of patients. Second, only patients who successfully converted to MSN returned for Visit 3 (351 patients); this should be taken into account when comparing results between Visit 1 and Visit 3 . Third, although standardized definitions of risk were given to investigators, these were qualitative in nature and were not in reference to any specific timeframe (eg, risk of abuse during the upcoming study, risk of abuse over the next day, 3 months, year, or lifetime). Another limitation is that the investigators were less familiar with some of the subjects, which might have affected their responses in judging risk. It was also noted that $\sim 18 \%$ of patients did not have a positive result for their prescribed opioid. This may be for many reasons. The patients may have taken their prescriptions irregularly or may be changing their medication more than the physician was aware. Also, the last dose of opioid may have been taken hours to a day earlier, and the resulting levels may have been below detectable levels on the UDT or the opioid was of a nature that is not readily detected on a UDT (eg, tramadol).

Despite these limitations, patient self-reports and UDT did confirm that there is a subset of patients who had historically engaged in aberrant behaviors with prescription opioid medication. Some patients reported each type of aberrant behavior, with the majority indicating overconsumption. Aberrant behaviors were present in a patient population that was initially screened to have no history of opioid and/or alcohol abuse and would otherwise be expected to be at lower risk for aberrant behaviors. It is important to identify risky behaviors in the pain patient population such as overconsumption and inappropriate administration or diversion of opioids. An absence of prior diagnosis of abuse may not preclude patients with chronic pain from exhibiting such behaviors. Appropriate screening and use of tools in clinical practice may help to identify when such behaviors occur and to enable appropriate patient counseling.

\section{Conclusion}

Efforts to provide appropriate pain management should coincide with efforts to reduce the problem of prescription opioid misuse, abuse, and diversion. In this study, we used two new questionnaires designed to assess the potential risk of patients for engaging in aberrant behaviors related to prescription opioid misuse, abuse, and diversion among patients with chronic pain. We compared the investigator assessment of patient risk for misuse, abuse, and diversion with that of patient self-reports of these activities. Although the majority of patients with risk assignments were assigned by the investigator as low risk for prescription opioid misuse, abuse, and diversion, many displayed aberrant behaviors according to SR-MAD and COMM and one-third had an abnormal UDT result during the study. The results from this study generally represent clinical results from a primary care setting. More research is needed to better understand the gap between the primary care physician assessment of potential risk for misuse, abuse, and diversion and the actual extent of these behaviors among patients with chronic pain.

\section{Acknowledgments}

This study was sponsored by King Pharmaceuticals, Inc., which was acquired by Pfizer Inc in March 2011. King Pharmaceuticals, Inc. was responsible for the protocol development, study conduct, and original analysis. The final analyses and development of the clinical study report was sponsored by Pfizer Inc. Medical writing support was provided by Vardit Dror, $\mathrm{PhD}$, of Engage Scientific Solutions and was funded by Pfizer Inc.

\section{Disclosure}

Carl L Roland, Glenn C Pixton, and Veeraindar Goli are employees of Pfizer Inc and were employees of King Pharmaceuticals, Inc. at the time the study was conducted. Beatrice Setnik and Kenneth W Sommerville were employees of Pfizer Inc when this manuscript was drafted and employees of King Pharmaceuticals, Inc. at the time the study was conducted. Robert Berke is the founding partner in a family practice group in western New York State, serves both as a medical consultant to the local county health department and as a geographic assistant professor in the Department of Social and Preventive Medicine, State University of New York at Buffalo, and holds Pfizer stock. Anne Calkins is an employee of the New York Spine \& Wellness Center and is a paid speaker for Pfizer, Inc. The authors report no other conflicts of interest in this work.

\section{References}

1. Institute of Medicine. Relieving Pain in America: A Blueprint for Transforming Prevention, Care, Education, and Research. Washington, DC: National Academy of Sciences; 2011.

2. Manchikanti L, Fellows B, Ailinani H, Pampati V. Therapeutic use, abuse, and nonmedical use of opioids: a ten-year perspective. Pain Physician. 2010;13(5):401-435. 
3. Paulozzi LJ, Jones CM, Mack KA, Rudd RA. Vital signs: overdoses of prescription opioid pain relievers - United States, 1999-2008. MMWR Morb Mortal Wkly Rep. 2011;60(43):1487-1492.

4. Volkow ND, McLellan TA. Curtailing diversion and abuse of opioid analgesics without jeopardizing pain treatment. JAMA. 2011;305(13): 1346-1347.

5. Substance Abuse and Mental Health Services Administration. Drug Abuse Warning Network, 2011: National Estimates of Drug-Related Emergency Department Visits. Rockville, MD: US Department of Health and Human Services; 2013. [HHS Publication No (SMA) 13-4760, DAWN Series D-39].

6. National Center for Health Statistics. Health, United States, 2012: With Special Feature on Emergency Care. Hyattsville, MD: CDC; 2013.

7. Chou R, Fanciullo GJ, Fine PG, Miaskowski C, Passik SD, Portenoy RK. Opioids for chronic noncancer pain: prediction and identification of aberrant drug-related behaviors: a review of the evidence for an American Pain Society and American Academy of Pain Medicine clinical practice guideline. J Pain. 2009;10(2):131-146.

8. Jones T, Moore T, Levy JL, et al. A comparison of various risk screening methods in predicting discharge from opioid treatment. Clin J Pain. 2012;28(2):93-100.

9. Moore TM, Jones T, Browder JH, Daffron S, Passik SD. A comparison of common screening methods for predicting aberrant drug-related behavior among patients receiving opioids for chronic pain management. Pain Med. 2009;10(8):1426-1433.

10. Passik SD, Kirsh KL, Casper D. Addiction-related assessment tools and pain management: instruments for screening, treatment planning, and monitoring compliance. Pain Med. 2008;9(Suppl 2): S145-S166.

11. Webster LR, Webster RM. Predicting aberrant behaviors in opioidtreated patients: preliminary validation of the Opioid Risk Tool. Pain Med. 2005;6(6):432-442.

12. Butler SF, Fernandez K, Benoit C, Budman SH, Jamison RN. Validation of the revised screener and opioid assessment for patients with pain (SOAPP-R). J Pain. 2008;9(4):360-372.

13. Butler SF, Budman SH, Fanciullo GJ, Jamison RN. Cross validation of the current opioid misuse measure to monitor chronic pain patients on opioid therapy. Clin J Pain. 2010;26(9):770-776.
14. Butler SF, Budman SH, Fernandez KC, et al. Development and validation of the current opioid misuse measure. Pain. 2007;130(1-2):144-156.

15. Ives TJ, Chelminski PR, Hammett-Stabler CA, et al. Predictors of opioid misuse in patients with chronic pain: a prospective cohort study. BMC Health Serv Res. 2006;6:46.

16. Brown J, Setnik B, Lee K, et al. Assessment, stratification, and monitoring of the risk for prescription opioid misuse and abuse in the primary care setting. J Opioid Manag. 2011;7(6):467-483.

17. Smith SM, Dart RC, Katz NP, et al; Analgesic, Anesthetic, and Addiction Clinical Trials, Translations, Innovations, Opportunities, and Networks (ACTTION) public-private partnership. Classification and definition of misuse, abuse, and related events in clinical trials: ACTTION systematic review and recommendations. Pain. 2013;154(11):2287-2296.

18. Setnik B, Roland CL, Sommerville KW. Amulticenter, primary-carebased, open-label study to assess the success of converting opioidexperienced patients with chronic moderate-to-severe pain to morphine sulfate and naltrexone hydrochloride extended-release capsules using a standardized conversion guide. J Pain Res. In press 2015.

19. Weissman DE, Haddox JD. Opioid pseudoaddiction - an iatrogenic syndrome. Pain. 1989;36(3):363-366.

20. Beaudoin FL, Straube S, Lopez J, Mello MJ, Baird J. Prescription opioid misuse among ED patients discharged with opioids. Am J Emerg Med. 2014;32(6):580-585.

21. Han H, Kass PH, Wilsey BL, Li CS. Increasing trends in Schedule II opioid use and doctor shopping during 1999-2007 in California. Pharmacoepidemiol Drug Saf. 2014;23(1):26-35.

22. Baumblatt JA, Wiedeman C, Dunn JR, Schaffner W, Paulozzi LJ, Jones TF. High-risk use by patients prescribed opioids for pain and its role in overdose deaths. JAMA Intern Med. 2014;174(5):796-801.

23. Mansbach RS, Schoedel KA, Kittrelle JP, Sellers EM. The role of adverse events and related safety data in the pre-market evaluation of drug abuse potential. Drug Alcohol Depend. 2010;112(3): $173-177$.
Journal of Pain Research

\section{Publish your work in this journal}

The Journal of Pain Research is an international, peer-reviewed, open access, online journal that welcomes laboratory and clinical findings in the fields of pain research and the prevention and management of pain. Original research, reviews, symposium reports, hypothesis formation and commentaries are all considered for publication.

\section{Dovepress}

The manuscript management system is completely online and includes a very quick and fair peer-review system, which is all easy to use. Visit http://www.dovepress.com/testimonials.php to read real quotes from published authors. 